\section{THE PUBLIC WELL-BEING-(continued).}

Health, will in turn only be possible through the enlightened support of the whole community. That it will be difficult for the Ministry to avoid what are commonly called politics is proved by the point of view of men like Dr. C. C. Weeks, who regards " alcohol and alcoholism as one of the great coefficients in all the damaged life and disease met with day by day in the natural life of this country." Sir George Newman, Chief Medical Officer of Health, has said that if we are to have a healthy nation we must first deal with alcohol, then with venereal disease, and then with feeble-mindedness-but the three are hand-in-hand. The point is that immediately a Government Department like the Ministry of Health shows a realisation of the dangers of alcohol and proposes the adoption of a scientific method of combating the evil, it is bound to come up against vested interests and thus to create strong party opposition.
That is one of the many serious difficulties that will continue to beset a Department whose administrative work and constructive policy must necessarily touch the ordinary life of the people at numerous points. These difficulties will only be overcome by an informed public opinion, and by skilled and tactful, as well as bold, handling on the part of the Minister himself and those who serve him.

For a long time in these columns we have done our best to support the Ministry of Health in its widest intentions, while criticising its work in important details; at the same time, we nave endeavoured to inform that special section of the public reached through our pages of the true relationship of the new Department of Health to the public and of its important bearing on the wellbeing of the community. We are glad to mow from many persons whose opinion we respect that these efforts have been widely appreciated.

\title{
Crime and Unemployment.
}

WE should like to know what warrant a correspondent has for his suggestion that the increase of crime of all kinds in different parts of the country is due to the enormous mass of unemployment which prevails, and which in turn produces idleness, as well as desperation caused by hunger and fear. In the first place, we have seen no police records which in any way support the statement that crime in this country-apart from the organised and wellrecognised political outbreaks of Sinn Fein extremists-has increased in recent months. 'Indeed, all the indications are the other way. It is a quite remarkable fact that during an unprecedented depression and disturbance of trade, produced or accompanied by a number of acute industrial wage disputes, in which nearly $3,000,000$ persons are out of work, the ordinary life of the nation has continued almost without noticeable interruption or disorder.

This preservation of order in circumstances of great temptation or provocation has been commented upon with admiration and surprise by the foreign Press in all parts of the world, and it certainly redounds to the credit of the British people, whose sang-froid and common sense have been put to an exacting test. The explanation seems partly to be this: that there has never been a peroid of trade depression in this country in which out-ofwork persons have suffered less real privation. The Prime Minister has been severely criticised for making a statement similar to this to the Dominion Premiers. But what he said was literally true. Not only have the working classes during, and immediately after, the period of war been bettes paid and (in the post-war period) better nourished than $\epsilon$ ver before in their history, not only have large numbers of the more far-sighted among them been able to save a good deal of money from their earnings; but the colossal system of unemployment doles (however undesirable from the point of view of national finances and in other aspects as well) has undoubtedly enabled large numbers of persons, who would otherwise have been entirely without the means of subsistence, to feed themselves after a fashion and generally to tide over the crisis. It seems to be just to say that the relatively good physical condition of the masses at the outset of the "slump" has counterbalanced the bad psychological effect of the sudden drop from prosperity to penury, and has thus contributed to keeping them patient, orderly, healthy, and hopeful.

\section{Home Helps Schemes.}

THE Health Committee of the Camberwell Borough Council has prepared what.it describes as a "workable" scheme for the provision of home helps, and mentions $£ 500$ as the cost to the rates for twelve months. The proposal is for the Infant Welfare Centres, Midwives' Associations, and Care Committees to be asked whether they can supply the names of suitable persons as home helps, and also to insert advertisements in the local papers. Persons willing to act as helps should be interviewed by a sub-committee and a register should be kept by the medical officer of health containing the names and addresses of the selected women. The women should be paid at the rate of 1 s. $6 \mathrm{~d}$. per hour for a forty-seven hour week. All applications for the services of helps should be considered on their merits. and persons provided with helps and who are in a position to make payments should be called upon to do so, the amounts to be fixed by the sub-committee on a sliding scale according to the family circumstances. The authorities at Birmingham appear to have developed a useful corps of home helps. A report of the Health Committee states that the arrangements for the supply of home helps to families during the confinement of the mother are now in operation, and proving to be a great boon. Fifty helps are employed, and a charge of $5 \mathrm{~s}$. per day is ordinarily made for their services. 